\title{
A CONSTITUIÇÃO DA INFÂNCIA NA SOCIEDADE MIDIÁTICA: notas para compreensão de outro universo infantil
}

\author{
The constitution of childhood in the mediatic society: \\ notes to understanding of another infantile universe
}

Aldo Pontes ${ }^{1}$

\section{Resumo}

Um ponto pacífico nos estudos sociológicos sobre a infância é que muito diferente do que comumente se costuma pensar, a infância, ou o sentimento de infância como entendemos hoje, é muito mais do que apenas uma fase na vida dos indivíduos. Concebida a partir de uma perspectiva histórico-cultural, essa se constitui como sendo uma invenção, uma criação do homem influenciado por forças políticas, sociais, econômicas e culturais. Dessa forma, à medida que a sociedade sofre mudanças mais amplas, a idéia de infância também estará sujeita a transformações. A ação da Indústria Cultural na constituição da infância torna-se ainda mais fácil em uma sociedade cada vez mais violenta, em que as brincadeiras comuns da infância, profundamente marcadas pelo lúdico, pela troca, pela socialização, pela criação, realizadas em espaços abertos como quintais, parques, praças, etc., saem de cena e dão lugar hoje a uma infância cada vez mais marcada pela eletronização, na qual cada criança, enclausurada em seus quartos individuais, consomem TV, videogame, internet, celular, etc., uma infinidade de ideologias e produtos especificamente criados para elas veiculados pelas mídias. Diante disso, na brevidade deste artigo, refletimos sobre a infância em nossa sociedade, marcada definitivamente pela ação das mídias e da Indústria Cultural.

Palavras-chave: Infância; Mídia; Ressignificação.

Docente da USF - Universidade São Francisco. Doutorando em Educação e Comunicação (FE-USP). Mestre em Tecnologia Educacional. Org./autor do livro Infância, Cultura e Mídia, dentre outros. e-mail: aldopontes@hotmail.com 


\section{Abstract}

A concurrent point in the sociological studies on childhood is that, quite different from what is generally thought, childhood - or the childhood feeling as we understand today - is much more than a single stage in the individuals' life. Conceived from a cultural-historical perspective, it is comprised as being an invention, a creation of the man, influenced by political, social, economical, and cultural forces. Thus, as the society suffers wider changes, the idea of childhood will also be subject to changes. The action of the Cultural Industry in the establishment of the childhood will become easier and easier in a society which is becoming more violent, in which the common children's games, deeply marked by the playful, the exchange, the socialization, the creation, carried out in open areas such as yards, parks, squares etc., leave the scene today and give place to a childhood strongly marked by the electronics world, in which each child, enclosed in his/her own bedroom, consumes TV, video games, Internet, mobile phone etc., an infiniteness of ideologies and products specifically designed to them and disclosed by the media. For this reason, in the briefness of this article, we will reflect about the childhood in our society, categorically marked by the action of the media and the Cultural Industry.

Keywords: Childhood; Media; Re-signification.

\section{Introdução}

\author{
Saiba: todo mundo foi neném \\ Einstein, Freud e Platão também \\ Hitler, Bush e Saddam Hussein \\ Quem tem grana e quem não tem \\ Saiba: todo mundo teve infância \\ Maomé já foi criança \\ Arquimedes, Buda, Galileu \\ e também você e eu \\ (Saiba-Arnado Antunes)
}

Um primeiro olhar sobre a letra habilidosamente composta por Arnaldo Antunes certamente não revela muito mais que a obviedade: ninguém escapa da infância. Até aqui, nada de novo. Agora levando em consideração os estudos sobre a infância, mais especificamente aqueles oriundos da sociologia, antropologia, psicologia social e áreas correlatas, temos todas as pistas para suspeitar que a infância vivenciada por Albert Einstein foi completamente diversa daquela vivida por Buda; que a infância de Adolf Hitler não foi a mesma experienciada por Galileu Galilei... Isso ocorre porque a infância, ${ }^{2}$ bem diverso do que comumente costumamos entender, precisa ser repensada e compreendida como algo mais que apenas uma fase na vida dos indivíduos.
Concebida a partir de uma perspectiva histórico-cultural, a infância constitui-se como sendo uma invenção, uma criação do homem moderno/burgês, influenciado por forças políticas, sociais, econômicas e culturais. Dessa forma, à medida que a sociedade sofre mudanças mais amplas, a idéia de infância também estará sujeita a transformações. Diante disso, nos questionamos como é a infância em uma sociedade marcada definitivamente pela ação dos interesses da Indústria Cultural e, conseqüentemente, das mídias, como a que vivemos hoje? É no enfreantamento do desafio de pensar em respostas plausíveis a essa questão que nos aventuramos neste texto. Estamos certos dos nossos limites de tempo e espaço neste texto, mas, mesmo assim, não abdicaremos de socializar um pouco do que encontramos no percurso da feitura de nossa tese de doutorado, que desenvolvemos na FE-USP, sob a orientação da Prof. ${ }^{a}$ Dr. ${ }^{a}$ Heloisa Dupas Penteado.

\section{Infância, indústria cultural e mídia televisiva: tecendo a trama}

Em qualquer ordem social [...] o poder transformador da
TV ocorre pelas contradicóes decorrentes dos interesses
diversos dos agentes sociais compreendidos pela Indústria
Cultural (Penteado, 1991, p. 49).

2 “O sentimento da infância não significa o mesmo que a afeição pelas crianças: correponde à consciência da articularidade infantil, é essa particularidade que distingüe essencialmente a criança do adulto, mesmo jovem.” (ARIÈS, 1981, p. 99). 
Mapeando o que dizem alguns autores das literaturas que tentam responder a questões similares a que propomos aqui, de forma ponderada ou radical, observamos que apontam de forma bastante recorrente ações agressivas da Indústria Cultural sobre a infância. A máquina movente que legitima essa ação continua sendo a televisão que, definitivamente instalada nos lares e em outros espaços do cotidiano, exerce o poder de moldar comportamentos, sugerir modismos, coagir ao consumo e inculcar valores (REZENDE; REZENDE, 2002).

$\mathrm{Na}$ sociedade midiática, desde a infância, o indivíduo é encantado pelo espetáculo veiculado pela mídia televisiva que, por sua própria constituição objetiva, veta a atividade mental (crítico-reflexiva) do espectador em troca de uma ilusão de prazer, fantasia, gozo... (ADORNO, 2002). Para Guy Debord (1997, p. 75), "o espetáculo é uma visão de mundo que se materializou, é a afirmação da aparência e a afirmação de toda a vida humana isto é, social - como simples aparência”. Assim, de acordo com Guy (1997, p. 75), o objetivo do espetáculo televisivo é convencer de que "o que aparece é bom, o que é bom aparece". Caracterizada dessa forma, na TV, comumente, a realidade surge no espetáculo e o espetáculo passa a ser real.

Mesmo não sendo a criança uma consumidora totalmente passiva da programação televisiva, pois sabemos que essa é também produtora de cultura (culturas da infância), sem uma ação mediadora da família (nos seus mais diversos arranjos), da escola..., o encantamento pelo espetáculo exibido na telinha da TV é inevitável. Isso ocorre pelo fato de nada se interpor entre a criança e a TV. Vale lembrar que em uma sociedade em que os pais têm pouco tempo para os filhos, a TV não se ausenta, não se cala, não se nega. A TV não frustra, não permite a dúvida, nem a angústia. Faz cessar tensões internas, faz sonhar. Assim, podemos inferir que a relação entre a criança e a TV é a relação com um objeto total (KEHL, 1991).

Por meio da TV, a Indústria Cultural não atinge apenas as crianças com maior poder aquisitivo, mas também aquelas que cotidianamente convivem com a escassez de recursos financeiros e até mesmo as que vivem abaixo da linha da pobreza. Como assinala Ferrés (1996, p. 79-80), “a televisão produz seus maiores efeitos socializadores nas camadas sociais e culturais mais frágeis. Em conseqüência, as crianças são umas presas fáceis e influenciáveis do meio". E a falta de uma educação mediadora aumenta a possibilidade de manipulação, antes de qualquer coisa, porque, quanto menos educação, mais ócio incontrolado e, portanto, mais tempo de exposição ao meio. Quando falamos em educação, estamos pensando em um processo educativo que oportunize, aos pequenos, orientações para um consumo autônomo e crítico da mídia televisiva.

O encantamento do telespectador mirim torna-se ainda mais fácil em uma sociedade cada vez mais violenta, em que as brincadeiras comuns da infância, profundamente marcadas pelo lúdico, pela troca, pela socialização, pela criação, realizada em espaços abertos, como quintais, parques, praças, etc., saem de cena e dão lugar hoje a uma infância cada vez mais marcada pela eletronização, na qual cada criança, enclausurada nos limites de sua casa, consome TV, videogame, Internet, telefone fixo e celular, etc., tecnologias midiáticas que trazem a ela uma infinidade de produtos anunciados em uma publicidade especificamente criada para ela. Para Chauí (1996), seguindo a dinâmica da sociedade capitalista, cabe aos meios midiáticos estimular de todas as formas possíveis o imaginário das crianças, com a finalidade de introduzir nesses indivíduos a necessidade de consumo e transformá-los em crianças consumidoras.

Em consonância com essas idéias, Henry Giroux (2004), analisando a ação da Disney no contexto social infantil, por exemplo, alerta que as crianças experimentam a influência cultural da Disney por conta da confusão de representações e de produtos encontrados em vídeos domésticos, shoppings, filmes "educacionais", bilheterias, programas populares de TV, restaurantes familiares e outras formas de extensão da marca.

Outro aspecto que contribui decisivamente para a constituição dessa infância consumidora do espetáculo midiático televisivo e seus produtos é o fato de as principais instituições reguladoras, formadoras na infância, a família e a escola, estarem paulatinamente mais distantes da realidade vivenciada pelas crianças, aos poucos deixando de ser referenciais para elas. A escola, na maioria das vezes, enclausurada a um currículo/ método de ensino, não dá conta da realidade; e a família (independente de seu arranjo), preocupada apenas em formar, em educar a criança para ter sucesso na vida adulta, acaba também perdendo sua relevância, deixando um vazio propício para o surgimento de uma nova e competente reguladora 
(formadora): a mídia televisiva. Nas palavras de Caparelli (2002, p. 133): “A importância da família e da escola como mediadoras do conhecimento foi diminuindo com o aparecimento dos meios massivos de comunicação".

Ainda em relação à saída de cena das famílias, hoje muito preocupadas com o futuro brilhante de seus filhos, merece nossa atenção observar as estratégias que são utilizadas para isso, pois é cada vez mais comum a submissão dos pequenos a rotinas estressantes que começam na segunda e invadem os fins de semana: balé, caratê, natação, escola, aula particular, campeonato disso, campeonato daquilo... Dessa forma, não há dúvida de que as crianças estarão preparadas para a vida adulta, para o competitivo mercado de trabalho da sociedade moderna, pois já na infância estão acostumadas com o estresse da constante corrida contra o tempo, típica do mundo dos adultos.

Kehl (2004) chama a atenção para os possíveis danos dessa realidade, afirmando que, em relação à brincadeira, a situação das crianças das classes média e alta é muito perversa, pois as crianças-com-agenda desaprendem de brincar. Os pais estão preocupados em prepará-las para o futuro, para fazer sucesso no mercado de trabalho do mundo capitalista, para corresponder a padrões de eficiência sempre mais exigentes na nossa imaginação do que na realidade. Segundo ela, os pais se esquecem de deixar um tempo para que elas aprendam a viver. Acostumadas a uma vida programada, tutelada por profissionais, babás e motoristas, essas crianças desenvolvem um horror ao vazio.

Sobre essa falta de atenção às crianças por parte das famílias contemporâneas, há registros de estudos realizados nos Estados Unidos que comprovam que naquele país, os adultos dedicam exclusivamente à criança, em média, sete minutos por dia. Dedicar significa estar com ela sem fazer outra coisa, como ler jornal, falar ao telefone, etc. Tal realidade é apontada por Souza; Campos (2003) quando indicam que: $\mathrm{O}$ tempo compartilhado entre pais e filhos é cada vez mais escasso: trabalha-se cada dia mais para o aumento do poder aquisitivo (e conseqüentemente do consumo), e atualmente a mulher tem uma contribuição crescente na fatia produtiva da população, ficando bastante tempo fora de casa. Os pais chegam tarde em casa, as crianças são atarefadas, as refeições são solitárias ou feitas fora do lar. A família se reúne cada vez menos para conversar sobre o cotidiano... Mesmo considerando os novos modelos/arranjos familiares, essa realidade continua sendo bastante recorrente.

Nesse contexto, o preço pago é a privação da criança de dois fatores fundamentais para o desenvolvimento de sua autonomia: a brincadeira e o humor descompromissados, sem hora, tempo marcados, cronometrados. Existe algo mais repressivo do que a frase: "Brincadeira tem hora?". Vale retomar aqui as palavras de Kehl (2004) quando indica que a brincadeira floresce no tempo vazio. Mais ainda: floresce quando a cabeça está vazia. A autora chama a atenção para as muitas formas de repressão, castração da brincadeira. De acordo com a autora, herdamos dos mais velhos a idéia de idente frase carrega em seu bojo que cabeça vazia é oficina do diabo. Subjacente a essa inocente frase, existe um forte mecanismo de castração a uma das marcas mais indeléveis da infância das crianças: a imaginação livre. Dessa forma, os adultos tentam privar as crianças de pensar bobagens, fazer travessuras e viver aventuras, mantendo-as ocupadas com alguma coisa. "Mas o diabo que se engendra numa cabeça vazia é o capetinha do faz-de-conta, do devaneio, da pura alegria de viver" (KEHL, 2004, p. 3).

Na concepção de Sayão (2004, p. 12), os pais têm a sua parcela de culpa pelo fato de as crianças entrarem no mundo adulto cada vez mais cedo. Isso ocorre quando os pais esquecem que, apesar de já considerarem seus filhos mocinhos ou mocinhas que precisam se comportar, esses ainda não adultos, mas sim crianças que têm uma etapa a ser vivida: "Até pouco tempo, as crianças brincavam de namorar, brincavam de ir ao salão de beleza, de médico, de dentista etc. Elas brincavam de ser gente grande". Fica claro aqui que na sociedade midiática há pouco tempo para ser criança, que cada vez mais a infância torna-se curta, considerando a expectativa de vida das pessoas.

Por outro lado, os pais não são os únicos, nem muitos menos os principais responsáveis pelo encurtamento da infância. $\mathrm{O}$ mundo contemporâneo elegeu a juventude como seu ícone maior, supervalorizando o ser jovem e prescindindo assim a infância. Essa realidade é comumente legitimada nas telas das mídias, as quais não se cansam de mostrar que ser jovem é sinônimo de atitude (SAYÃO, 2004).

Refletindo sobre o que assinala Sayão (2004), entendemos que o fruto dessa ideologia maciçamente propagada pelas mídias no mundo atual 
é que o tempo de ser criança precisa passar rapidinho para que a criança se torne logo um jovem, um adulto para ser "valorizada", "reconhecida" pela sociedade.

Face ao exposto, a impressão que temos é que novamente estamos diante de uma reconfiguração da idéia de infância, já que, como apresentamos em linhas gerais, as marcas da infância hoje são outras bem diferentes das da vivenciada há algumas décadas. "Estamos em via de exorcizar uma imagem bicentenária de criança e trocá-la pela imagética do jovem adulto" (POSTMAN, 1999, p. 139).

Para Sarmento (2006, p. 17), trata-se de um fato consumado, o lugar da infância na contemporaneidade é um lugar em mudança. A modernidade estabeleceu uma norma da infância, em larga medida definida pela negatividade constituinte:

A criança não trabalha, não tem acesso direto ao mercado, não se casa, não vota nem é eleita, não toma decisões relevantes, não é punível por crimes (é inimputável). Essa norma assenta num conjunto estruturado de instituições, regras e prescrições que se encarregam da "educação" da criança, especialmente a escola e a família.

Alguns autores mais extremistas, como Postman (1999, p. 31), por exemplo, já há algum tempo, vêm sinalizando o desaparecimento da infância. Para ele, em um mundo letrado, ser adulto implica ter acesso a segredos culturais codificados em símbolos não naturais. Num mundo letrado, as crianças precisam transformar-se em adultos. Entretanto, "num mundo não letrado não há necessidade de distinguir com exatidão a criança e o adulto, pois existem poucos segredos e a cultura não precisa ministrar instrução sobre como entendê-la".

Em seus estudos sobre a relação mídia e educação, Postman (1999, p. 94), a partir de uma perspectiva cultural, afirma que o fato de a família vir gradualmente perdendo o controle sobre a vida de seus filhos, aliado à crescente força que a mídia televisiva vem ganhando na sociedade, contribui diretamente para o desaparecimento da linha divisória entre a infância e a vida adulta. Nas palavras desse autor:

A televisão destrói a linha divisória entre infância e idade adulta de três maneiras, todas relacionadas à sua acessibilidade indiferenciada: primeiro, porque não requer treinamento para apreender sua forma; segundo porque não faz exigências complexas nem à mente nem ao comportamento, e terceiro porque não segrega seu público.

Menos radicais que Postman (1999), cremos que o que está realmente desaparecendo é a visão moderna-burguesa que se tinha/tem da infância caracterizada pela inocência, ingenuidade, candura, singeleza, pureza..., como algo naturalizado, imutável, igual para todos independente de questões sociais, econômicas, políticas e culturais. Assim, em uma sociedade que tem a cultura profundamente marcada pela ação das mídias, como a nossa, por exemplo, ser criança, adolescente, adulto ou idoso é determinado por múltiplos interesses (políticos, econômicos...), merecem destaque dentre esses os da Indústria Cultural, representados, divulgados e perpetuados pelas mídias, em especial a televisiva.

\section{Notas finais}

Após incursionarmos um pouco pelos caminhos da infância para entendê-la hoje, sentimos a necessidade de ampliar o nosso olhar para ver não mais apenas a infância, mas as muitas infâncias que estão por aí. Apesar de ser uma categoria etária geracional plural que deve ser pensada sempre como um processo em constantante tranformação, a Indústria Cultural insiste em se fazer presente em todas elas, em um exercício incansável de naturalizá-la, formatá-la, reificála. Condições necessárias para a continuidade de uma utilização mercantilista da categoria infância.

Apesar de caracterizada dessa maneira, é muito instigante saber que algumas marcas dessa categoria (infância) resistem, se perpetuam ao longo dos tempos, dentre essas, destacamos a cultura lúdica. Por meio de seus jogos e brincadeiras, as crianças recriam, transformam o seu mundo e o mundo dos adultos. Nesse sentido, chamamos atenção para a relevância de garantir, aos pequenos, espaços e momentos para que experienciem intensamente as diversas nuances da infância. Resgatar e fomentar uma infância dessa natureza é uma forma bastante razoável de burlar a dinâmica agressiva da Indústria Cultural e das mídias no cotidiano das crianças.

É fundamental que fique claro que, mesmo muitas vezes desrespeitosa com as crianças, pensamos que a televisão em si não pode ser considerada sozinha 
como sendo a grande responsável pelos inúmeros problemas que emergem do cotidiano infantil. Notese que subjacente a essa está a indústria cultural. Como bem nos lembra o professor Gómez (1990, p. 04): "No obstante los recursos y las características tecnológicas propias del medio televisivo y su particular definición social como institución, su influencia en la audiencia, aunque creciente e importante, no es ni única ni totalizadora."

A TV também pode em muito contribuir para o desenvolvimento das crianças, tanto para o seu lazer saudável como para uma formação autônoma e crítica dos pequenos. Como nos ensina Adorno (1995, p. 76), podemos identificar duas funções da TV na formação cultural dos indivíduos: a primeira tem a ver com uma ação deformativa (responsável pela divulgação e inculcação de ideologias - dominantes - para/na consciência dos espectadores); já a segunda teria sim uma ação formativa (o uso desse meio de comunicação para divulgação de informações e de esclarecimentos no sentido da construção de conhecimentos). Porém, não podemos esperar muito da TV em si, pois, mesmo sendo concessão pública, o compromisso primeiro assumido publicamente pelas tevês não é educar, mas sim entreter. É aí que defendemos a importância de uma mediação pedagógica da família, da escola, dos professores. Mestres que cotidianamente são mediadores na construção do conhecimento dos pequenos. "Trata-se de enriquecer a experiência, mas sem negá-la, de possibilitar uma leitura reflexiva e crítica, mas sem eliminar o prazer sensorial e emocional" (FERRÉS, 1996, p. 83). Em outras palavras, instigá-los a exercitar as muitas possibilidades de ver e viver o cotidiano.

\section{Referências}

ADORNO, T. W. Educação e emancipação. São Paulo: Paz e Terra, 1995.

Indústria cultural e sociedade. São Paulo: Paz e Terra, 2002.

ARIÈS, Philippe. História social da criança e da família. Rio de Janeiro: LTC, 1981.

CAPARELLI, Sérgio. Infância digital e cibercultura. In: PRADO, José Luiz Aidar (Org.). Crítica das práticas midiáticas, da sociedade de massa às ciberculturas. São Paulo: Hacker, 2002. p. 111-129.
CHAUÍ, Marilena de Souza. Conformismo e resistência: aspectos da cultura popular no Brasil. São Paulo: Brasiliense, 1996.

FÉRRES, Juan. Televisão e educação. Porto Alegre: Artes Médicas, 1996.

GIROUX, Henry A. Os filmes da Disney são bons para seus filhos? In: STEINBERG, Shirley R.; KINCHELOE, Joe. L. (Org.). Cultura infantil: a construção corporativa da infância. Rio de Janeiro: Civilização Brasileira, 2004. p. 415.

GÓMEZ, Guillermo Orozco. La audiencia frente a la pantalla: una exploración del proceso de recepción televisiva. Dialogos de la com unicación, Lima, n. 30, jun. 1990.

GUY, Debord. A sociedade do espetáculo. São Paulo: Martins Fontes, 1997.

KEHL, Maria Rita. Imaginar e pensar. In: NOVAES, Adauto. Rede imaginária. São Paulo: Companhia das letras, 1991.

Infâncias roubadas. Revista Ao Mestre com Carinho Online, 2004. Disponível em: <http:/ /www.aomestrecomcarinho.com.br>. Acesso em: 27 de ago. 2004.

PENTEADO, Heloisa Dupas. Televisão e escola, conflito ou cooperação? São Paulo: Cortez, 1991.

POSTMAN, N. O desaparecimento da infância. Rio de Janeiro: Graphia, 1999.

REZENDE, A. L. M. de; REZENDE, N. B. de. A tevê e a criança que te vê. São Paulo: Cortez, 2002.

SAMENTO, Manuel Jacinto. Infâncias, tempos e espaços: um diálogo com Manuel Jacinto Sarmento. Currículo sem Fronteiras, v. 6, n. 1, p. 1524, jan./jun. 2006.

SAYÃO, Rosely. Há pouco tempo para ser criança. Folha de S. Paulo, São Paulo, 18 nov. 2004. Suplemento Folha Equilíbrio, p. 12.

SOUZA, Solange J.; CAMPOS, Cristiana C. G. de. Mídia, cultura do consumo e constituição da subjetividade na infância. Psicologia Ciência e Profissão, Brasília: v. 23, n. 1, p. 12-21, 2003.

Recebido em: 04/02/2007 Received in: 02/04/2007 Aceito em: 04/04/2007 Accepted in: 04/04/2007 